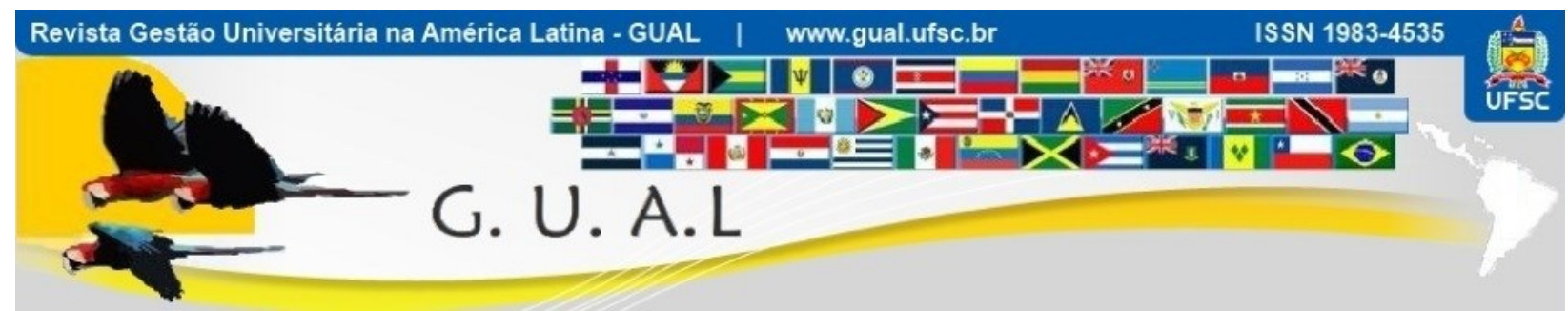

DOI: http://dx.doi.org/10.5007/1983-4535.2016v9n3p45

\title{
DESENVOLVIMENTO DE COMPETÊNCIAS NA GRADUAÇÃO EM ADMINISTRAÇÃO - PERCEPÇÃO DOS ALUNOS
}

\section{SKILLS DEVELOPMENT ON ADMINISTRATION GRADUATION - STUDENTS PERCEPTION}

Tereza Cristina Batista de Lima, Doutora

Universidade Federal do Ceará - UFC tereza@prograd.ufc.br

Luis Eduardo Brandão Paiva, Mestrando Universidade Federal do Ceará - UFC eduardobrandao@alu.ufc.br

Liana Queiroga Correia, Graduada Universidade Federal do Ceará - UFC liana.q.c@gmail.com

João Paulo Cavalcante de Aquino, Graduado Universidade Federal do Ceará - UFC joaopauloaquino10@gmail.com

João Felipe Barbosa Araripe Silva, Mestre Universidade Federal do Ceará - UFC felipe.araripesilva@gmail.com

Recebido em 11/setembro/2014

Aprovado em 22/abril/2016

Sistema de Avaliação: Double Blind Review

Esta obra está sob uma Licença Creative Commons Atribuição-Uso. 


\title{
RESUMO
}

O sucesso das organizações depende das pessoas que a integram e de suas competências, adquiridas, em parte, pela formação proporcionada pelas Instituições de Ensino Superior. Reconhecendo a importância dessa temática, este artigo se propõe analisar as competências profissionais adquiridas na graduação em Administração em uma universidade pública federal, sob a visão de 195 alunos concluintes deste curso. Para obtenção dos resultados, aplicou-se um questionário para identificar o perfil do estudante e as competências adquiridas por meio do curso. Os resultados apontam que o curso oferecido auxilia no desenvolvimento das competências profissionais, especialmente as competências de conhecimento/cognitiva e a social.

Palavras-chave: Competências. Formação. Desenvolvimento.

\begin{abstract}
The success of organizations depends on the people who comprise it and their skills, acquired in part by training provided by institutions of higher education. Recognizing the importance of this topic, this article aims to analyze the professional skills acquired in the administration graduation in a Public University, under the vision of 195 students attending this course. To obtain the results, we applied a questionnaire to identify the profile of the student and the skills acquired through the course. The results show that the course offered assists in the development of professional skills, especially knowledge / cognitive and social skills.
\end{abstract}

Keywords: Skills. Training. Development. 


\section{INTRODUÇÃO}

A realidade atual do mercado pode ser compreendida, entre outros fatores, pela exigência e maior conhecimento por parte do consumidor, que requer das empresas não só produtos e serviços de qualidade para atenderem suas necessidades, mas um comportamento socialmente e ambientalmente responsável, inclusive no tratamento dado aos funcionários da organização. A concorrência entre as empresas está mais acirrada, pressionando-as a repensar suas estratégias de negócios e formas de organização do trabalho, assim como levando-as a buscar profissionais cada vez mais qualificados e dotados de competências variadas. Abordando esse assunto, Marinho e Poffo (2013) mencionam que a busca da qualidade no mundo empresarial deve ser dinâmica e contínua, assim como no âmbito educacional, e este deve ser avaliado ao longo do tempo por estudos e experiências que verifiquem sua qualidade.

Nesse contexto, as Instituições de Ensino Superior (IES) exercem um papel fundamental pois são responsáveis, de acordo com a Lei de Diretrizes e Bases (LDB) da educação nacional estabelecida pelo Ministério da Educação (MEC), por proporcionar aos alunos graduandos uma formação que possibilite a qualificação para o mercado de trabalho e o aperfeiçoamento profissional, para que assim, possam contribuir com o desenvolvimento da sociedade brasileira.

Essa lei, instituída em 1996, contribuiu para a mudança no cenário acadêmico, pois a partir dela surgiram decretos norteadores da composição curricular dos cursos de graduação no país, trazendo a ideia de competências profissionais como um conceito a ser adotado pelas IES: "encorajar o reconhecimento de conhecimentos, habilidades e competências adquiridas fora do ambiente escolar, inclusive as que se referirem à experiência profissional julgada relevante para a área de formação considerada" (CONSELHO NACIONAL DA EDUCAÇÃO, 2001).

Por se tratar de um curso com uma formação generalista e diversificada, o curso de Administração engloba desde áreas ligadas a finanças e cálculos até às relacionadas com administração de recursos humanos, cabendo a cada Instituição estabelecer, com a liberdade dada a partir da LDB, a composição do currículo que será oferecido aos alunos.

Assim, esse trabalho tem como objetivo geral analisar as competências profissionais adquiridas por meio do curso presencial de Administração, sob a visão dos alunos concluintes de uma universidade pública federal. 
Como objetivos específicos, pretende-se analisar o grupo de competências que mais se destacaram na percepção dos alunos, o conjunto de competências que os alunos menos desenvolveram, bem como analisar as diferenças de percepção entre homens e mulheres.

A escolha desse tema de pesquisa foi motivada pela atual valorização dada ao indivíduo no sucesso das organizações, tornando a formação acadêmica do mesmo fundamental para atender às exigências do mercado.

\section{COMPETÊNCIAS}

O conceito de competência deriva do final da Idade Média, período em que o termo era utilizado restritamente à linguagem jurídica e significava que determinada corte, tribunal ou indivíduo era competente para realizar um dado julgamento. A expressão passou a ser utilizada para qualificar pessoas capazes de realizar um bom trabalho (RAMOS; BENTO, 2007).

Outro importante trabalho sobre o estudo de competências foi o de Lyle Spencer Jr. e Signe Spencer (1993). Eles buscaram explicar as diferentes perspectivas sobre o conceito de competências por meio da analogia a um iceberg, de modo que a parte visível é representada pelas habilidades e conhecimentos, e a parte submersa é representada por valores, traços e motivações do indivíduo, ou seja, a primeira está mais ligada ao desempenho profissional e a segunda à personalidade, condicionando e comportamento (CEITIL, 2007).

Complementando essa teoria do iceberg, Ellison e Davies (1999), afirmaram que a parte não visível do iceberg corresponde aos inputs, ou seja, àquilo que as pessoas trazem para suas funções, suas características pessoais, motivações e valores; e a parte visível do iceberg são os outputs, ou seja, os comportamentos concretos e as ações desenvolvidas na função exercida, demonstrando conhecimentos e habilidades.

O termo competência se encontra definido de várias formas entre os teóricos da Administração (MILKOVICH; BOUDREAU, 2006). Todavia, a perspectiva da competência como o conjunto de conhecimentos, habilidades e atitudes se encontra com grande aceitação na literatura especializada.

\subsection{COMPETÊNCIAS ORGANIZACIONAIS}

A importância de abordar o estudo das competências dentro das organizações se dá pelo atual cenário de competitividade e rápidas mudanças, que exigem novos comportamentos 
dos profissionais inseridos nesse contexto. Acerca do mercado atual, Teixeira e Wissmann (2013) afirmam que a organização contemporânea deve ser constituída de processo sistemático e contínuo que integre conhecimento, aprendizagem e competências.

De acordo com Ruas (2010), a noção de competência tem aparecido como uma forma de reanalisar as interações entre as pessoas, com seus saberes e suas capacidades, e as organizações, com suas demandas dos processos de trabalho essenciais e relacionais. Essa interação é cada vez mais estudada e analisada como uma dimensão estratégica da organização, considerando os recursos internos da empresa como principais fatores de competição.

Corroborando a ideia de Ruas (2010), Fischer et al. (2009) afirmam que os estudos sobre competências organizacionais surgiram com a teoria da visão da firma baseada em recursos (Resources Based View - RBV), em que a principal fonte de vantagens competitivas está na aplicação superior de recursos que estão contidos dentro da empresa. Essa teoria defende que a diferença de desempenho entre as empresas é atribuída às diferenças nos recursos detidos por cada uma delas e na sua capacidade de utilização, sendo mais importante a forma de aplicação e coordenação desses recursos, para a geração de vantagens, do que os recursos em si.

A partir da teoria RBV, surgiu outro conceito, bastante presente na literatura: a noção de competências essenciais de uma organização. Elas são definidas como "o conjunto de habilidades e tecnologias que habilitam uma companhia a proporcionar um benefício particular para os clientes" (HAMEL; PRAHALAD, 2005, p. 231). Segundo estes mesmos autores, as competências essenciais obedecem a três critérios: oferecerem reais benefícios aos consumidores; são difíceis de imitar; e dão acesso a diferentes mercados.

\subsection{COMPETÊNCIAS INDIVIDUAIS}

No eixo de formação da pessoa podem ser encontradas características intrínsecas do indivíduo, adquiridas por meio da vivência em sociedade e dos valores absorvidos nas relações; no eixo da formação educacional podem-se adquirir os saberes teóricos, saberes procedurais e os saberes cognitivos; já no eixo da experiência profissional, encontram-se os saberes procedurais, operacionais, experienciais, relacionais e cognitivos (LE BOTERF, 2003). 
Fleury e Fleury (2008, p. 30), abordam competências como fonte de valor para o indivíduo e para a organização, definindo competência como sendo: "Um saber agir responsável e reconhecido, que implica mobilizar, integrar, transferir conhecimentos, recursos, habilidades, que agreguem valor econômico à organização e valor social ao indivíduo".

Torna-se evidente o aspecto polissêmico do termo competência na medida em que emergem diferentes percepções e abordagens sobre o assunto.

Godoy et al. (2009) ao discutirem sobre o desenvolvimento das competências de alunos do curso de Administração, elaboram um quadro comparativo com diferentes grupos de competências, embasados pelas teorias de autores já citados nesse trabalho, como Fleury e Fleury (2008, 2010), além da inclusão do modelo proposto por Cheetham e Chivers (2005).

Para a construção do modelo, Cheetham e Chivers (2005) utilizaram ampla gama de modelos existentes, protocolos para descrição de competências, extensa literatura sobre educação e desenvolvimento profissional e um estudo empírico desenvolvido com profissionais de vinte diferentes profissões. O objetivo principal era procurar elementos coerentes dentro das diferentes abordagens e propor um modelo holístico (GODOY et al., 2009).

De acordo com Godoy et al. (2009), o modelo possui três componentes centrais considerados importantes para a obtenção de um desempenho efetivo, são eles: competência de conhecimento/cognitiva, competência funcional e competência comportamental ou pessoal.

Tomando como base a teoria proposta por Fleury e Fleury (2008) e o modelo utilizado por Godoy et al. (2009) serão detalhados os grupos de competência encontrados a partir da relação entre essas teorias e que darão suporte ao entendimento e análise do questionário utilizado nesse trabalho.

\section{O PAPEL DO ADMINISTRADOR NAS ORGANIZAÇÕES}

O papel do profissional de administração está relacionado ao ambiente de incertezas e de mudanças, cabendo a ele, através dos conhecimentos e habilidades adquiridos, não só escolher o caminho certo, mas ser inovador e criativo nessa escolha.

Segundo Fayol (1990), administrar é prever, no sentido de planejar o futuro e traçar um plano de ação; organizar, colocando à disposição os recursos necessários para o correto 
funcionamento da organização; comandar, no sentido de dirigir e delegar funções às pessoas; coordenar, unindo esforços; e controlar o que foi planejado, para alcançar os objetivos. Já na visão de Drucker (1998), o papel do administrador é cumprir a missão da organização em que trabalha, e tornar o trabalho produtivo e o profissional realizado, além de administrar impactos e responsabilidades sociais.

Atualmente, o curso de Bacharelado em Administração agrega o maior número de matrículas no ensino superior, segundo o Instituto Nacional de Estudos e Pesquisas Educacionais Anísio Teixeira (INEP) existia 833.042 alunos matriculados no país em 2012. São 1.805 cursos contabilizados até 2010 (INEP, 2013).

\subsection{A FORMAÇÃO DO ADMINISTRADOR NO BRASIL E O CURSO DE ADMINISTRAÇÃO NA UFC}

O ensino de Administração está relacionado com o processo de desenvolvimento do país, marcado pelos governos de Getúlio Vargas, de caráter nacionalista, e de Juscelino Kubistchek, caracterizado pela abertura econômica. De acordo com Teixeira e Wissmann (2013), foi na década de 40 que o papel do Administrador ganhou mais força, pois aumentava a necessidade de mão de obra qualificada, tendo sua importância ressaltada no primeiro Congresso Brasileiro de Economia, em 1943. Nesse período, o processo de industrialização foi acentuado, ocasionando uma valorização do ensino superior, inclusive na área de Administração, devido à necessidade de mão de obra de nível superior que pudesse lidar com a realidade empresarial complexa da época.

A regulamentação da profissão veio em 1965, por meio da Lei $n^{0} 4.769$, que tornou o acesso ao mercado profissional privativo dos portadores de títulos expedidos pelo sistema universitário. Essa lei fixou as diretrizes e bases da educação no Brasil, ampliando os campos para profissionais de Administração.

De acordo com Rodrigues (2010), a Administração, como pesquisa e como área profissional, refere-se a um campo que lida com problemas concretos, porém as soluções propostas são intangíveis, uma vez que envolvem relações entre pessoas, recursos materiais e tempo.

Rodrigues (2010) aponta uma questão que vem sendo abordada recentemente por diversos autores: a distância entre o conhecimento científico em Administração e a prática profissional. 
Sobre esse assunto, Ruas (2010) acredita que os processos de formação estão concentrados, sobretudo, no desenvolvimento de um dos principais recursos da competência: o conhecimento. Porém, o problema entre sistemas de formação e desenvolvimento de competências está na dificuldade de transferir e adaptar os resultados da formação no ambiente de trabalho. Contudo, conclui: "as iniciativas de formação continuam indispensáveis e todos os esforços devem ser mobilizados para torná-las mais efetivas e estratégicas" (RUAS, 2010, p. 251).

É importante reconhecer, para a análise entre a estrutura do curso e o desenvolvimento de competências, que o currículo do curso de Administração deve ser dinâmico; que requer atenção em função das demandas do mercado; que a participação do aluno é fundamental para seu aprendizado e que as técnicas participativas deverão predominar as técnicas tradicionais; que os professores devem ter competência cognitiva e, além disso, é necessário treinamento em estratégias de ensino e prática de sala de aula (MOREIRA et al., 1995).

O curso de Administração da Universidade Federal do Ceará (UFC) é o mais antigo entre os cursos de Administração do estado, criado em 1978, inicialmente apenas no período diurno, passando a oferecer o período noturno só em 1997 com o objetivo de dar oportunidade às pessoas já inseridas no mercado de trabalho. Atualmente, são ofertadas oitenta vagas para cada turno, por ano, tendo o tempo de conclusão padrão de quatro anos e meio e o tempo máximo de sete anos. O currículo do curso apresenta todas as disciplinas com quatro créditos, com exceção das disciplinas Estágio Supervisionado I e II (cinco créditos), totalizando 194 créditos equivalentes à 3.104 horas/aula, estando esse total dividido entre disciplinas obrigatórias, de formação específica (habilitação), optativas e atividades complementares (UNIVERSIDADE FEDERAL DO CEARÁ, 2006).

É necessário estabelecer o papel da formação universitária no desenvolvimento de competências profissionais, verificando como a contribuição da Universidade se revela pertinente com o objetivo ao qual ela se propõe por meio do projeto pedagógico e das diretrizes do MEC.

\section{METODOLOGIA}

Será apresentado, primeiramente, a classificação da pesquisa, considerando os objetivos, os meios e a natureza dos dados coletados. Em seguida, será relatada a população e 
a amostra e os critérios para escolha das mesmas. Por fim, será mostrado o método utilizado para a análise e o tratamento dos dados obtidos.

\subsection{CLASSIFICAÇÃO DA PESQUISA}

Por se tratar de um estudo que visa estabelecer a relação entre o desenvolvimento de competências e o curso de Administração da UFC, bem como identificar essas competências, essa pesquisa pode ser classificada como descritiva.

Quanto ao tipo de dado coletado, pode-se definir como sendo primário, pois estes são coletados com o propósito de completar um projeto de pesquisa e o pesquisador se envolve em todos os aspectos de transformação dos dados, como por exemplo, coleta, análise e interpretação de dados. Dessa forma, "qualquer projeto de pesquisa que exija a criação e a implementação de um survey dará a origem a dados primários" (HAIR et al., 2005, p. 98).

O processo da pesquisa é o método utilizado para a coleta e a análise dos dados e, nesse caso, tratando-se de uma pesquisa descritiva, utiliza-se o método quantitativo, pois objetiva a mensuração de fenômenos, envolve a coleta de dados e a aplicação de testes estatísticos para identificar a relação entre as variáveis analisadas (COLLIS; HUSSEY, 2005).

\subsection{POPULAÇÃO E AMOSTRA}

Nesse trabalho, a população alvo consiste nos alunos do curso presencial de graduação em Administração da Universidade Federal do Ceará - UFC que concluirão o curso nos dois semestres subsequentes à pesquisa.

A escolha da população alvo foi influenciada pelo objetivo da pesquisa, a qual se propõe a analisar as competências profissionais desenvolvidas por meio do curso de Administração da UFC. Dessa forma, é necessário definir uma amostra que seja composta por alunos que tenham concluído a maior parte do curso, pois assim, eles serão capazes de avaliar o que a pesquisa requer e, possuem uma visão mais ampla dos conteúdos e competências trabalhadas ao longo do curso de Administração.

$\mathrm{Na}$ pesquisa em questão será utilizado o procedimento não probabilístico, ou seja, a seleção de elementos para a amostra não é necessariamente feita com o objetivo de ser estatisticamente representativa da população, cabendo ao pesquisador usar métodos subjetivos, como experiência, conveniência e conhecimento, para selecionar os elementos da amostra (HAIR et al., 2005). 
O tamanho da amostra foi determinado de acordo com a quantidade de concluintes do curso, que possuía 200 alunos matriculados em Monografia no segundo semestre de 2013, ou seja, concluindo o curso. A análise fatorial supõe que o tamanho de uma amostra seja maior ou igual a 100, e como regra geral, “o mínimo é ter pelo menos cinco vezes mais observações do que o número de variáveis a serem analisadas" (HAIR et al., 2009, p. 108). Os autores complementam que, o ideal é ter dez vezes o número de variáveis, ou seja, uma amostra de 200 pessoas. Levando em consideração que o questionário aplicado apresenta vinte variáveis, o tamanho da amostra compreende 195 respondentes.

\subsection{COLETA E ANÁLISE DOS DADOS}

No método de survey utilizado nessa pesquisa serão utilizados questionários auto administrados. Esse procedimento é usado para obter grande quantidade de dados, normalmente em forma de números, consistindo em um padrão de perguntas com respostas limitadas (HAIR et al., 2005). No questionário, foi utilizada a escala Likert ordinal para mensurar as opiniões dos respondentes e avaliar a intensidade com que alguém concorda com o conjunto de afirmações. Foi utilizada a escala de seis pontos com o objetivo de obter maior precisão do quanto a pessoa concorda ou discorda da afirmação.

O questionário é composto por duas partes: uma destinada à coleta de informações pessoais do respondente, tais como, idade, sexo, período em que estuda, se exerce atividade remunerada e o motivo da escolha do curso, e a outra composta de vinte sentenças, com valor variando de 0 ("discordo totalmente") a 5 ("concordo totalmente"), acerca das competências profissionais, que podem ser adquiridas por meio do curso de Administração da UFC, em que o aluno irá avaliar qual o nível de participação do curso na aquisição dessas.

A montagem do questionário foi feita tomando como base o modelo proposto por Cheetham e Chivers (2005) que consiste em abordar diferentes elementos sobre a noção de competência e relacioná-los com os conceitos de Fleury e Fleury (2008), identificando cinco tipos de competência.

A análise fatorial será do tipo exploratória, pois esse método fornece informação sobre quantos fatores são necessários para melhor representar os dados, de modo que as variáveis são relacionadas com cada fator por uma estimativa de carga fatorial (HAIR et al., 2009).

Para verificar a confiabilidade do questionário e a consistência da escala aplicada utilizou-se o Alfa de Cronbach, um coeficiente de confiabilidade que pode variar de 0 a 1 , 
tendo como valores aceitáveis o coeficiente mínimo de 0,6 (HAIR et al., 2009). Na tabulação e na análise dos dados foi utilizado o software SPSS na versão 20.

\section{ANÁLISE E DISCUSSÃO DOS RESULTADOS}

Nesta seção, serão mostrados os resultados obtidos, envolvendo os aspectos sóciodemográficos da amostra, as competências que mais se destacaram e as menos desenvolvidas no curso, bem como a análise das diferenças entre as percepções de homens e mulheres.

\subsection{CARACTERIZAÇÃO DOS RESPONDENTES}

Os questionários foram respondidos por 195 estudantes. Entre o grupo pesquisado, o gênero masculino compreende $63 \%$ dos estudantes respondentes, enquanto o feminino representa 37\%. Esse dado mostra uma característica do curso de administração: a predominância do gênero masculino, apesar do crescente número de mulheres na profisssão, conforme mostra a pesquisa do CFA, em 2011, em que o número de mulheres cresceu $67 \%$ em 17 anos.Em relação à idade dos respondentes, verifica-se uma predominância entre 22 e 23 anos (42\%). Entretanto, de acordo com a Figura 1, o percentual de alunos com 24 anos e acima de 25 anos também é considerável (29\%).

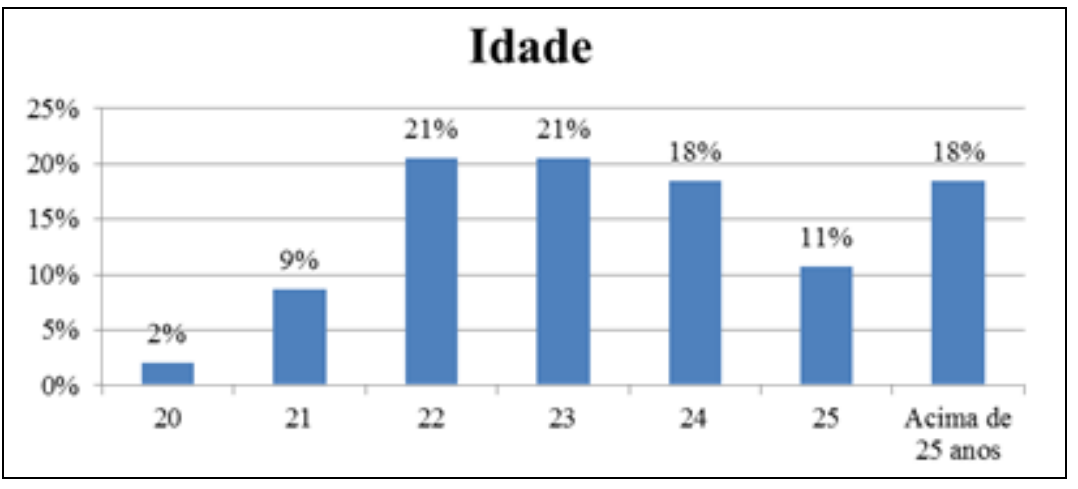

Figura 1 Idade.

Fonte: Pesquisa.

Em relação à atividade remunerada, 79\% dos estudantes questionados afirmaram que estão exercendo, atualmente, atividade remunerada. Dentre os respondentes que afirmaram exercer alguma atividade remunerada, a maior parte recebe até $\mathrm{R} \$ 3.390,00$, sendo que 40,9\% recebem até $R \$ 1.356,00$ (até 2 salários mínimos) e 43,5\% recebem valores entre $R \$ 1.356,01$ a R\$3.390,00 (de 2 a 5 salários mínimos). 
A Tabela 1 mostra os resultados da indagação acerca da escolha pela graduação em administração. A maior parte dos alunos optou pelo curso pensando nas oportunidades do mercado de trabalho, ao marcarem a opção "Amplo mercado de trabalho" (35\%), seguida de "Formação generalista e abrangente" (24\%).

Tabela 1 Motivo da escolha do curso.

\begin{tabular}{lcc}
\hline & Frequência & Percentagem \\
\hline Formação generalista e abrangente & 53 & $23 \%$ \\
Amplo mercado de trabalho & 80 & $35 \%$ \\
Vocação & 21 & $9 \%$ \\
Abrir negócio próprio & 33 & $14 \%$ \\
Influência de outro administrador & 15 & $7 \%$ \\
Atuar em empresa familiar & 19 & $8 \%$ \\
Outros & 7 & $3 \%$ \\
Total & 228 & $100 \%$ \\
\hline
\end{tabular}

Fonte: Pesquisa.

A partir da obtenção desses dados, fornecidos através da primeira parte do questionário, serão apresentados, a seguir, os resultados obtidos por meio da análise da segunda parte do questionário, mostrando a percepção dos alunos acerca da contribuição do curso de Administração no desenvolvimento de competências profissionais.

\subsection{TESTES DE CONFIABILIDADE E ANÁLISE FATORIAL}

Nesta seção apresentam-se os resultados obtidos com os métodos estatísticos utilizados no tratamento dos dados. A seguir, apresenta-se a verificação da confiabilidade do questionário, a adequação dos dados à Análise Fatorial, o agrupamento das variáveis correlacionadas em dimensões nomeadas de acordo com referencial teórico e o percentual do grupo de competências que foram desenvolvidos por meio do curso. Nas variáveis (sentenças) do questionário nos grupos de competência escolhidos foi utilizada a Análise fatorial. Essa análise é adequada para a redução de variáveis, sendo indicada para identificar quais tipos de competências são influenciadas pelo curso.

A significância da análise foi comprovada através do teste de esfericidade de Bartlett e o Kaiser-Meyer-Olkin (KMO), que indicaram a adequação dos dados para a realização da Análise Fatorial. 
A partir desse teste, são identificadas as variáveis que devem ser omitidas da Análise fatorial por não apresentar uma correlação considerada boa com as outras variáveis. Dessa forma, quatro sentenças foram desconsideradas, pois obtiveram coeficiente de correlação (comunalidade) inferior a 0,5 .

Para a escolha do número de fatores utilizou-se o método de rotação Varimax, que maximiza a soma das variâncias das cargas fatoriais, fornecendo uma clara separação entre os fatores (HAIR et al., 2009). Assim, na Tabela 2 são evidenciadas as variáveis que apresentam maior carga fatorial nos fatores.

Tabela 2 Determinação dos fatores.

\begin{tabular}{|c|c|c|}
\hline Fatores e Variáveis & $\begin{array}{l}\text { Cargas } \\
\text { fatoriais }\end{array}$ & Comunalidades \\
\hline \multicolumn{3}{|l|}{ Competência Técnico-Profissional } \\
\hline $\begin{array}{l}\text { Emitir pareceres e perícias administrativas gerenciais, } \\
\text { organizacionais, estratégicas e operacionais. }\end{array}$ & 0,809 & 0,70 \\
\hline Capacidade para realizar consultoria em gestão e administração. & 0,76 & 0,66 \\
\hline $\begin{array}{l}\text { Capacidade para elaborar, implementar e consolidar projetos em } \\
\text { organizações. }\end{array}$ & 0,728 & 0,60 \\
\hline \multicolumn{3}{|l|}{ Competência Comportamental/Pessoal } \\
\hline Comunicar-me na forma escrita e verbal de maneira clara e objetiva. & 0,801 & 685 \\
\hline Estabelecer comunicações interpessoais e intergrupais eficazes. & 0,787 & 632 \\
\hline Comunicar-me com segurança em processos de negociação. & 0,745 & 644 \\
\hline \multicolumn{3}{|l|}{ Competência de Conhecimento/Cognitiva } \\
\hline Identificar e definir problemas, bem como desenvolver soluções. & 0,797 & 690 \\
\hline Pensar estrategicamente a tomada de decisão. & 0,721 & 623 \\
\hline Elaborar e propor modificações nos processos de trabalho. & 0,705 &, 532 \\
\hline \multicolumn{3}{|l|}{ Competência Social } \\
\hline Ter iniciativa perante situações novas ou desafiadoras. & 0,666 & ,558 \\
\hline $\begin{array}{l}\text { Ter consciência da qualidade e das implicações éticas do meu } \\
\text { exercício profissional. }\end{array}$ & 0,659 &, 519 \\
\hline Adaptar-se às novas situações e/ou pressões de trabalho. & 0,648 & ,619 \\
\hline $\begin{array}{l}\text { Buscar o aperfeiçoamento contínuo da qualidade dos trabalhos sob } \\
\text { minha responsabilidade. }\end{array}$ & 0,54 & ,503 \\
\hline \multicolumn{3}{|l|}{ Competência Funcional } \\
\hline $\begin{array}{l}\text { Raciocinar de forma lógica e analítica utilizando operações com } \\
\text { valores e formulações matemáticas. }\end{array}$ & 0,86 & ,786 \\
\hline Refletir criticamente sobre a esfera da produção de bens e serviços. & 0,58 & 624 \\
\hline Transferir conhecimentos adquiridos a colegas e a outras pessoas. & 0,539 & ,575 \\
\hline
\end{tabular}

Fonte: Pesquisa. 
A construção dos cinco fatores permite explicar, conforme a Tabela 3, 62,2\% das variações das sentenças, tendo o primeiro fator com maior participação no entendimento das variações da amostra.

Tabela 3 Participação dos fatores nas variações das sentenças.

\begin{tabular}{lccc}
\hline \multirow{2}{*}{ Fatores } & \multicolumn{3}{c}{ Autovalores } \\
\cline { 2 - 4 } Competência Técnico-Profissional & Total & \% de Variação & \% Acumulada \\
Competência Comportamental & 4,418 & 27,611 & 27,611 \\
Competência de Conhecimento/Cognitiva & 1,766 & 11,040 & 38,651 \\
Competência Social & 1,470 & 9,185 & 47,836 \\
Competência Funcional & 1,245 & 7,782 & 55,618 \\
\hline
\end{tabular}

Fonte: Pesquisa.

A partir dos fatores formados pela Análise Fatorial, foi calculado o Alfa de Cronbach de cada grupo de competências, para validar e analisar o nível das competências que são desenvolvidas no curso de Administração. A partir desse cálculo, identificou-se que apenas um dos grupos analisados apresentou o valor abaixo do limite, porém, o grupo será considerado válido, já que foi formulado a partir da Análise Fatorial. Portanto, os cinco grupos são considerados válidos para esta pesquisa.

Por fim, a Tabela 4 demonstra os valores referentes ao desenvolvimento de cada grupo de competências por meio da faculdade de Administração. Esses resultados podem ser vistos por observação da coluna "Média" e "Quartis", que demonstram o percentual de concordância, com a aquisição das competências profissionais sugeridas por meio do curso. Além disso, observa-se o desvio padrão da amostra e se houve respondentes que marcaram a opção mínima ( 0 - Discordo totalmente) ou máxima (5 - Concordo totalmente).

Tabela 4 Grupo de competências desenvolvidas.

\begin{tabular}{lccccccc}
\hline & Média & $\begin{array}{c}\text { Desvio- } \\
\text { padrão }\end{array}$ & Mínimo & Máximo & \multicolumn{3}{c}{ Quartis } \\
\cline { 5 - 8 } & & & & 25 & 50 & 75 \\
Competência Técnico-Profissional &, 6516 &, 181 & 0,00 & 1,00 &, 53 &, 67 &, 80 \\
$\begin{array}{l}\text { Competência Comportamental } \\
\text { Competência de }\end{array}$ &, 6930 &, 189 & 0,00 & 1,00 &, 60 &, 73 &, 80 \\
Conhecimento/Cognitiva &, 7480 &, 136 &, 33 & 1,00 &, 67 &, 73 &, 80 \\
Competência Social &, 7304 &, 145 &, 10 & 1,00 &, 65 &, 75 &, 80 \\
Competência Funcional &, 6962 &, 152 &, 20 & 1,00 &, 60 &, 73 &, 80 \\
\hline
\end{tabular}

Fonte: Pesquisa. 
Percebe-se com esta tabela, que todos os grupos de competência apresentam valores acima de 65\% na média, indicando que as competências profissionais sugeridas são consideravelmente desenvolvidas por meio do curso de Administração.

\subsection{ANÁLISE DOS GRUPOS DE COMPETÊNCIA DESENVOLVIDOS}

$\mathrm{O}$ resultado da pesquisa mostrou que, de forma geral, o curso contribuiu para o desenvolvimento das competências profissionais. Porém, é importante analisar cada grupo de competência individualmente, começando pelo grupo de maior destaque e finalizando com o grupo considerado menos desenvolvido pelos alunos concluintes.

A Figura 2 mostra o percentual que os respondentes atribuíram, na escala que vai de 0 a 5, para cada variável relacionada ao grupo da Competência de Conhecimento/Cognitiva, com o valor da Média próximo de $75 \%$ de concordância com a indagação da pesquisa. É importante ressaltar que o questionamento feito aos alunos no questionário foi: "O curso de administração me ajudou a desenvolver a seguinte competência". Dessa forma a resposta seria dada pelo nível de discordância ( 0 a 2) ou de concordância (3 a 5) com a competência.

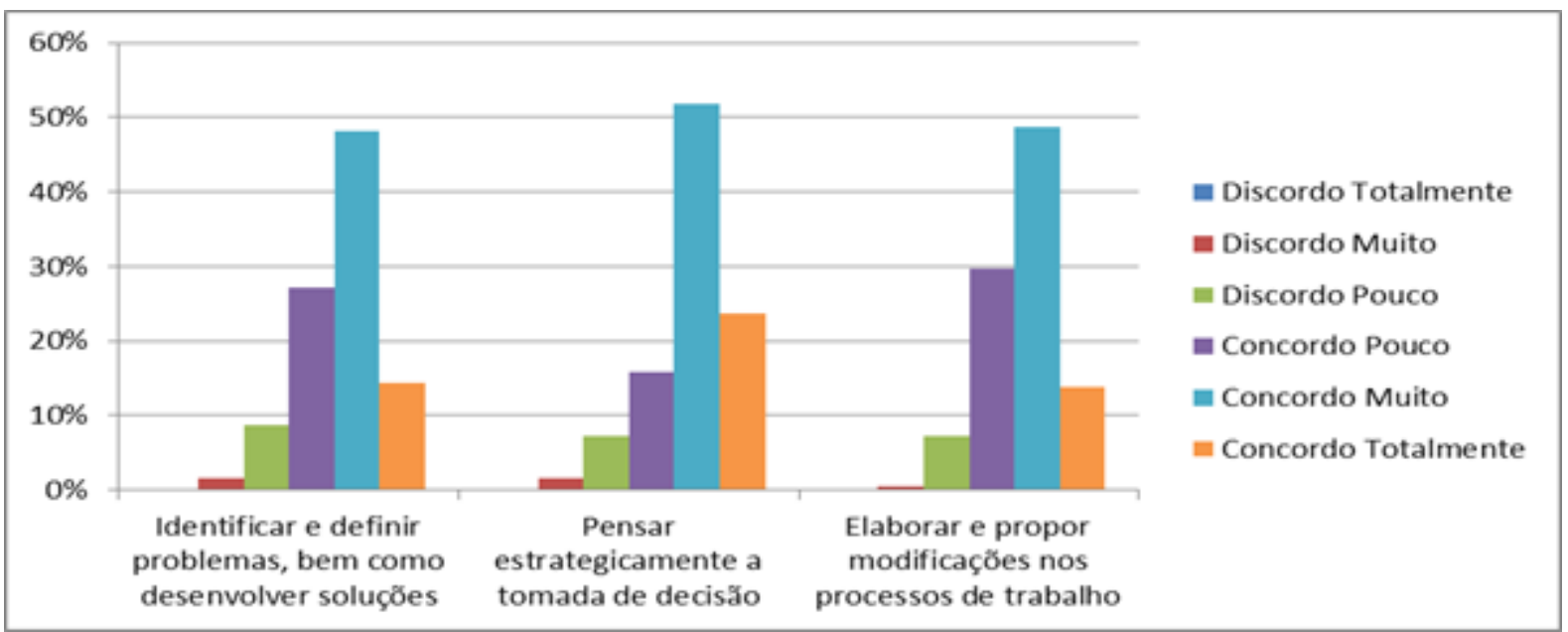

Figura 2 Competência de Conhecimento / Cognitiva. Fonte: Pesquisa.

Conforme a Figura 2 mostra, nas três variáveis propostas, o nível de concordância dos alunos é alto, estando acima de $80 \%$ em cada uma. Vale ressaltar que nesse grupo não houve nenhum aluno que marcou a opção "Discordo totalmente", demonstrando a percepção uniforme da importância do curso na aquisição dessas competências. Em suma, a aquisição dessa competência pode ser entendida como a demonstração de conhecimentos, habilidades e atitudes que são gerados por meio do conhecimento. 
$\mathrm{Na}$ Figura 3, é possível perceber que o nível de concordância em relação à contribuição do curso no desenvolvimento das competências sociais foi de aproximadamente $80 \%$ em cada uma das variáveis.

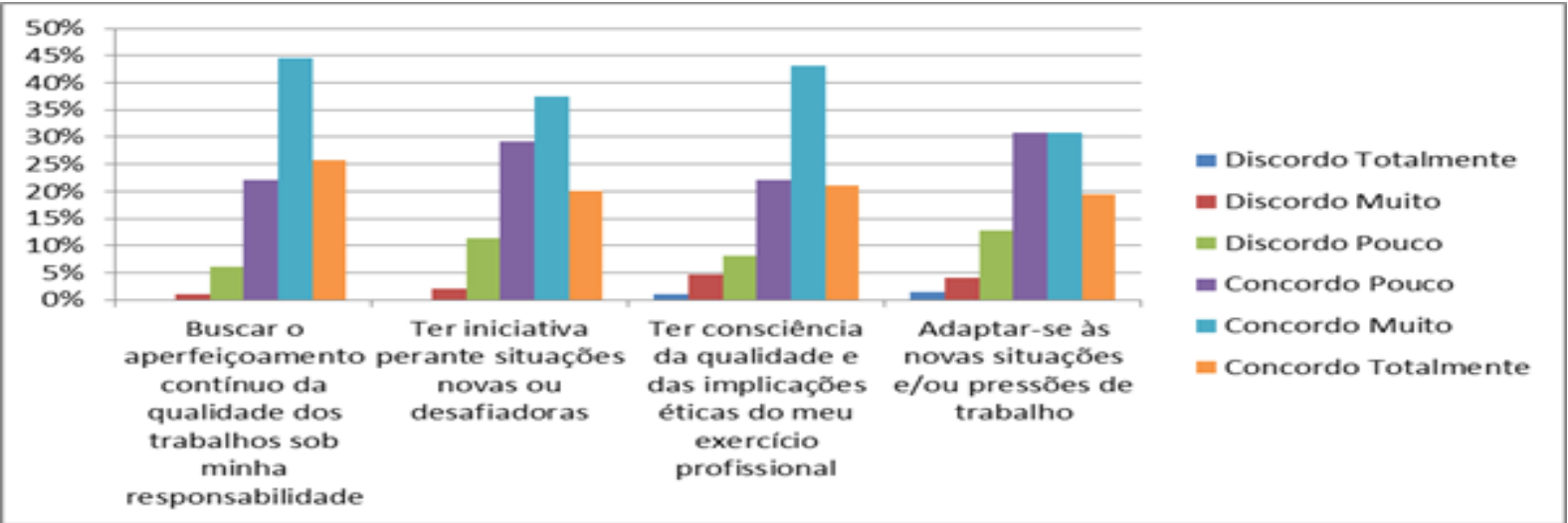

Figura 3 Competência Social.

Fonte: Pesquisa.

Na Figura 3 a variável relacionada à adaptação a novas situações e a pressões de trabalho apresentou respostas bem divididas quando se refere ao nível de concordância.

Esse resultado pode ser explicado por esta competência está voltada mais para uma questão subjetiva dos alunos do curso, ou seja, a adaptação, e por isso, não ensinada/aprendida ou não percebida no curso de administração da Universidade Federal do Ceará.

O terceiro grupo mais destacado na percepção dos alunos foi o da Competência Funcional, composto por três variáveis que dizem respeito à capacidade de transferir conhecimentos a outras pessoas, ao raciocínio lógico e ao raciocínio analítico dos alunos do curso de administração.

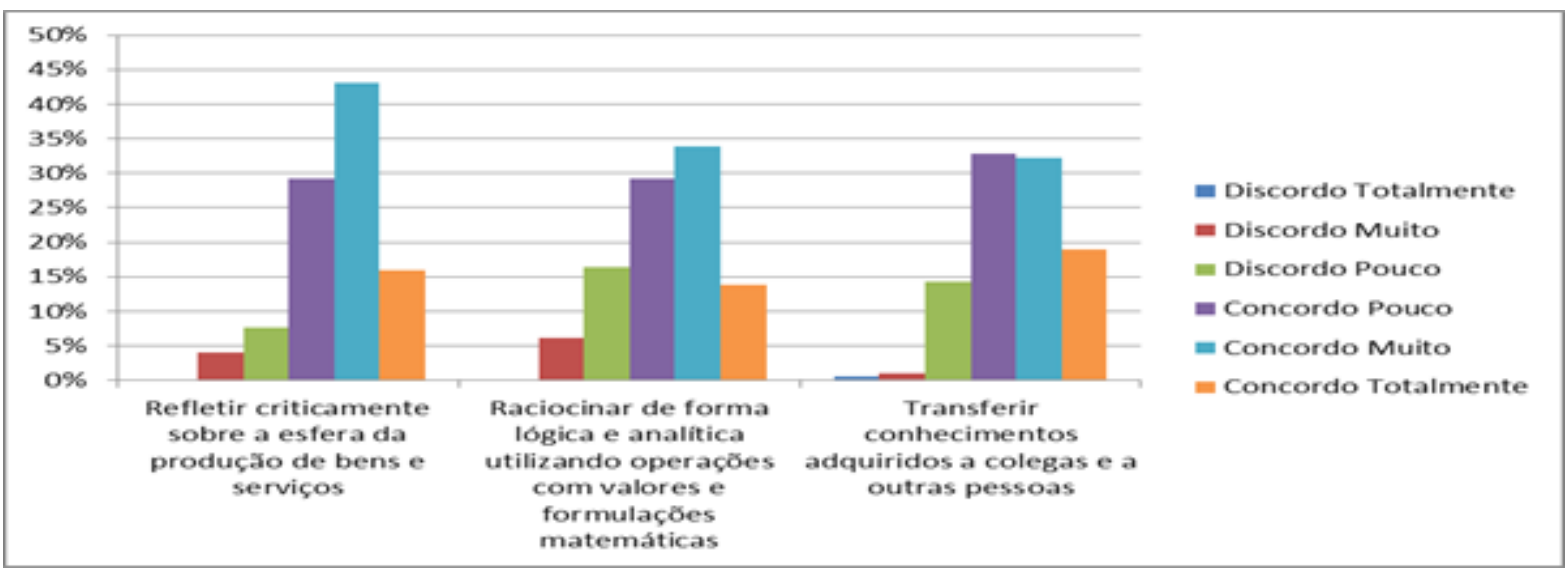

Figura 4 Competência Funcional.

Fonte: Pesquisa. 
Conforme a Figura 4, o nível de concordância dos alunos em relação a esse grupo está entre $75 \%$ e $80 \%$, porém, as respostas foram mais dispersas na variação da escala, o que mostra uma diversidade na percepção dos estudantes. O quarto grupo de competências profissionais desenvolvidos por meio do curso foi o da Competência Comportamental, composto por três variáveis que dizem respeito à capacidade de comunicar-se com segurança, de maneira adequada nas formas escrita e verbal e a forma eficaz com outras pessoas. A Figura 5, o nível de concordância no grupo está acima de $75 \%$.

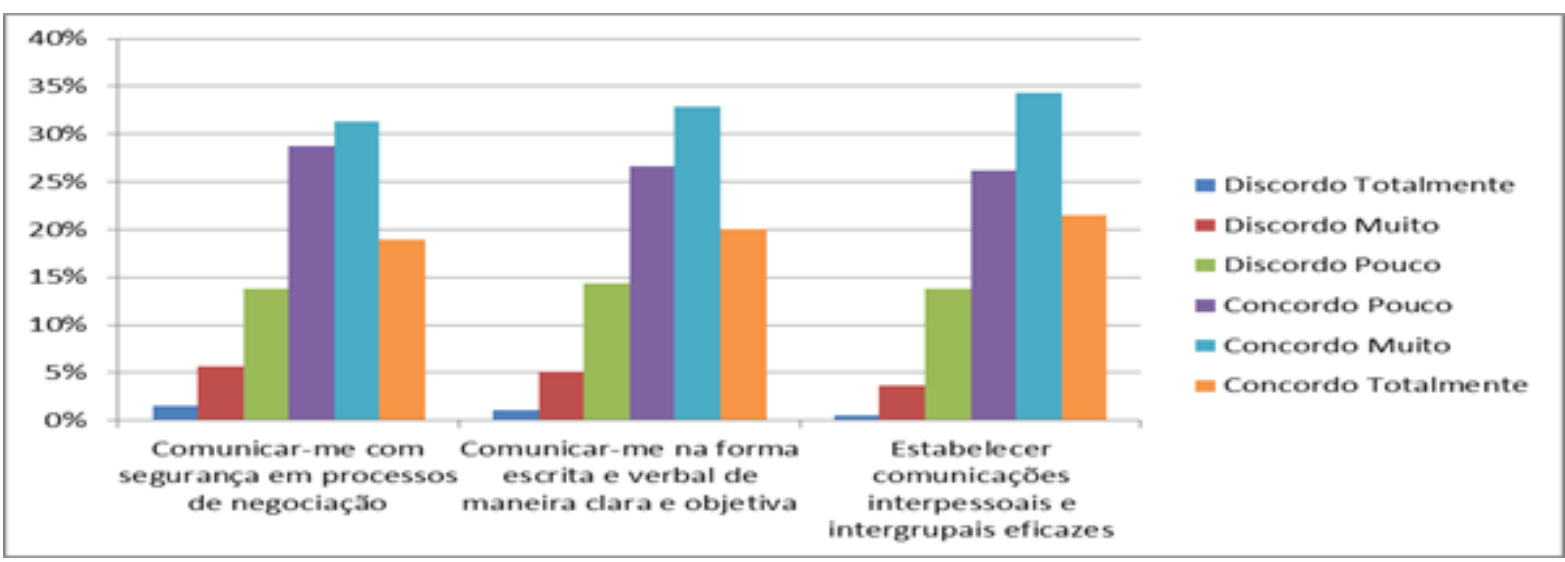

Figura 5 Competência Comportamental.

Fonte: Pesquisa.

Por fim, o grupo de competências de menor destaque na percepção dos alunos foi o da Competência Técnico-Profissional, composto por três variáveis que abordam sobre a capacidade de elaborar e de implementar projetos, de realizar consultoria e de emitir pareceres administrativos. A Figura 6 demonstra, o nível de concordância dos alunos situa-se por volta de $70 \%$.

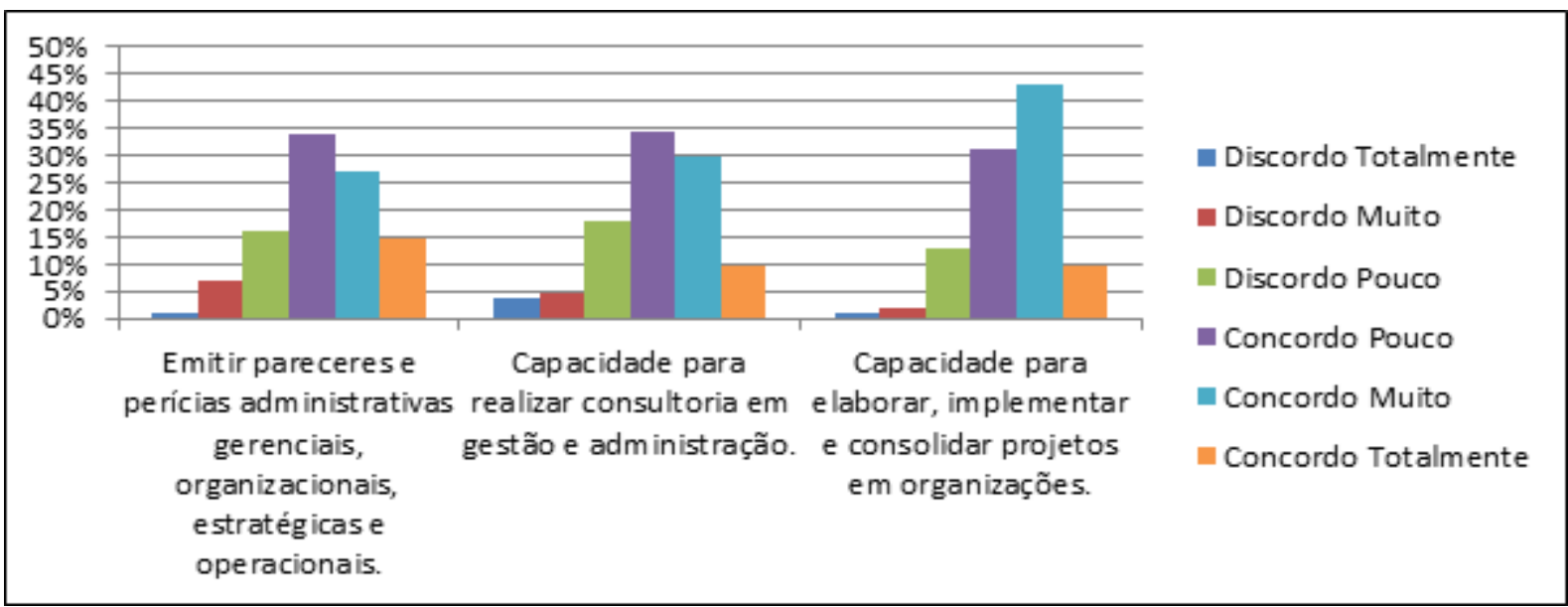

Figura 6 Competência Técnico-Profissional.

Fonte: Pesquisa. 
Percebe-se, também, que o percentual de pessoas que marcaram "Concordo Totalmente" é pequeno, demonstrando incerteza por parte dos alunos acerca da contribuição do curso de administração no desenvolvimento desse grupo. Porém, a variável que se refere à capacidade para elaborar, programar e consolidar projetos em organizações apresenta o nível de concordância um pouco acima de $80 \%$, refletindo que nesse aspecto o curso contribui consideravelmente para a aquisição dessa competência.

Tabela 5 Teste de média.

\begin{tabular}{|c|c|c|c|c|c|}
\hline \multirow{2}{*}{ Dimensões } & \multicolumn{2}{|c|}{$\begin{array}{c}\text { Teste Levene para Igualdade } \\
\text { de Variâncias }\end{array}$} & \multicolumn{3}{|c|}{ Teste $\mathrm{t}$ de Médias } \\
\hline & $\mathrm{F}$ & Valor $p$ & $\mathrm{t}$ & $\begin{array}{l}\text { Grau de } \\
\text { Liberdade }\end{array}$ & Valor $p$ \\
\hline $\begin{array}{l}\text { Competência Técnico- } \\
\text { Profissional }\end{array}$ &, 118 &, 732 &,- 314 & 193 &, 754 \\
\hline Competência Comportamental &, 015 & ,903 & 1,552 & 193 & ,122 \\
\hline $\begin{array}{l}\text { Competência de } \\
\text { Conhecimento/Cognitiva }\end{array}$ &, 041 &, 840 & 1,392 & 193 &, 165 \\
\hline Competência Social & ,364 &, 547 & 2,934 & 192 & ,004 \\
\hline Competência Funcional & 2,641 &, 106 & ,200 & 192 &, 841 \\
\hline
\end{tabular}

Fonte: Pesquisa.

Para concluir a análise dos resultados, faz-se necessário, conforme os objetivos pretendidos com essa pesquisa, identificar se o desenvolvimento das competências profissionais varia quanto ao gênero. Para isso, foi aplicado o teste de média entre os gêneros masculino e feminino, conforme na tabela 5 acima.

O teste de Levene permite averiguar acerca da homogeneidade das variâncias entre os grupos e o teste $t$ identifica se há ou não diferença significativa, estatisticamente, entre as médias, de modo que se o valor de $\mathrm{p}$ for inferior a 0,05 admite-se que a diferença é significativa estatisticamente.

Nesse estudo, somente o grupo da Competência Social mostrou diferença em relação a homens e mulheres, ou seja, esse grupo de competências é desenvolvido de maneira distinta quanto ao gênero. Para analisar como essa diferença se comporta, a tabela 6 mostra o percentual da média de homens e de mulheres acerca do desenvolvimento de cada grupo de competências profissionais. 
Tabela 6 Diferença entre gênero.

\begin{tabular}{lcccc}
\hline & Gênero & $\begin{array}{c}\text { Tamanho } \\
\text { Amostra }\end{array}$ & Média & Desvio padrão \\
\hline Competência Técnico- & Feminino & 72 &, 6463 &, 18711 \\
Profissional & Masculino & 123 &, 6547 &, 17824 \\
Competência Comportamental & Feminino & 72 &, 7204 &, 18610 \\
Competência de & Masculino & 123 &, 6770 &, 18992 \\
Conhecimento/Cognitiva & Feminino & 72 &, 7657 &, 13520 \\
Competência Social & Masculino & 123 &, 7377 &, 13624 \\
Competência Funcional & Feminino & 72 &, 7694 &, 15326 \\
& Masculino & 122 &, 7074 &, 13555 \\
\hline
\end{tabular}

Fonte: Pesquisa.

Percebe-se, portanto, que apenas o grupo da Competência Social apresenta uma diferença significativa na média, refletindo uma diferença na percepção de homens e mulheres acerca do desenvolvimento dessas competências. Ressaltando que, entre os gêneros, o feminino demonstrou que desenvolveu melhor essa competência por meio da formação no curso de administração, apresentando uma média superior ao grupo masculino.

\section{CONCLUSÃO}

Este estudo teve como objetivo geral analisar as competências profissionais adquiridas por meio do curso presencial de graduação em Administração da UFC. Para isso, além do estudo teórico acerca do assunto em questão, foi aplicado um questionário aos alunos concluintes, o qual pretendia caracterizar os respondentes e identificar o grupo de competências profissionais mais desenvolvidos, por meio do curso, entre os estudantes.

Os questionários foram aplicados na própria UFC, a maioria em sala de aula, no período diurno e noturno, entre 18 e 29 de novembro de 2013, com os estudantes que concluiriam a graduação nos próximos dois semestres.

Verificou-se que os respondentes são, em sua maioria, do gênero masculino, com idade predominante de 22 e de 23 anos. Além disso, 79\% da amostra exercem atividade remunerada e dentre estes, a maioria com a faixa salarial entre $\mathrm{R} \$ 1.356,01$ e $\mathrm{R} \$ 3.390,00$. No que se refere ao turno em que realizam o curso, a maioria dos alunos estuda à noite, e o motivo para a escolha do curso, indicado pela maioria, foi a existência de amplo mercado de trabalho.

O resultado mostrou que os quatro grupos, designados de Competência TécnicoProfissional, Competência Social, Competência Comportamental, Competência de 
Conhecimento/Cognitiva e Competência Funcional, são desenvolvidos pelo curso, já que mais de $65 \%$ dos respondentes afirmaram terem adquirido essas competências com auxílio da graduação.

O primeiro objetivo específico proposto buscou identificar qual o grupo foi mais desenvolvido na percepção nos alunos, sendo observado que a Competência de Conhecimento/Cognitiva e a Competência Social foram as mais destacadas, com percentual de concordância de aproximadamente $80 \%$.

Esse resultado mostra que o curso oferece recursos adequados para que os alunos possam identificar e solucionar problemas, decidir estrategicamente, ter consciência ética no exercício da profissão, ter iniciativa, entre outros.

O segundo objetivo procurou avaliar o grupo de competências considerado menos desenvolvido pelos alunos, verificando que a Competência Técnico-Profissional teve, aproximadamente, $25 \%$ no nível de discordância, com exceção da terceira variável que obteve apenas $16 \%$.

Esse resultado infere que a instituição de ensino pesquisada poderia rever o ensino dos conhecimentos referentes à capacidade para realizar consultoria em administração e para emitir pareceres nas diversas áreas da profissão, já que essas competências apresentaram relativa discordância quanto à contribuição da universidade na percepção dos estudantes.

O terceiro objetivo examinou se há diferença no desenvolvimento das competências devido ao gênero, obtendo como resposta a uniformidade na visão dos alunos em quase todos os grupos de competência, exceto no da Competência Social que apresentou uma diferença estatisticamente significativa.

Dessa forma, em relação à capacidade de ser proativo diante de novas situações, de ter consciência da qualidade e das implicações éticas do trabalho exercido, as mulheres conseguem desenvolver melhor essas competências por meio do curso do que os homens.

Para pesquisas futuras, sugere-se um estudo que englobe instituições públicas e privadas, investigando se há diferença na percepção desses alunos quanto ao desenvolvimento das competências. Além disso, uma análise que possibilite a descoberta de quais competências são mais requeridas dos alunos no exercício de suas atividades nas empresas e a investigação de quais disciplinas e atividades são mais importantes para a aquisição das diferentes categorias de competências profissionais. 


\section{REFERÊNCIAS}

CEITIL, M. (Org.). Gestão e desenvolvimento de competências. Lisboa: Sílabo, 2007.

CHEETHAM, G.; CHIVERS, G. E. Professions, competence and informal learning. Edward Elgar Publishing, 2005.

COLLIS, J.; HUSSEY, R. Pesquisa em Administração: um guia prático para alunos de graduação e pós-graduação. Porto Alegre: Bookman, 2005.

DAVIES, B.; ELLISSON, L. School Leadership for the 21 st Century: a competency and knowledge approach. London: Routledge, 1999.

DRUCKER, P. F. A profissão de Administrador. São Paulo: Pioneira, 1998.

FAYOL, H. Administração industrial e geral: previsão, organização, coordenação, controle. São Paulo: Atlas, 1990.

FISCHER, A. L.; DUTRA, J. S.; AMORIM, W. A. C. Gestão de Pessoas: desafios estratégicos das organizações contemporâneas. São Paulo: Atlas, 2009.

FLEURY, A.; FLEURY, M. T. L. Estratégias empresariais e formação de competências: um quebra-cabeça caleidoscópico da indústria brasileira. São Paulo: Atlas, 2008.

FRANCIATTO, C.; MOREIRA, D. A.; MASCARENHAS, K. L. FERREIRA, A. A. O que eles pensam sobre formação de administradores no país. Revista de Administração de Empresas, [São Paulo], p. 41-52, mar./abr. 1995. Disponível em: $<$ http://rae.fgv.br/sites/rae.fgv.br/files/artigos/10.1590_S0034-75901995000200016.pdf >. Acesso em: 6 nov. 2013.

GODOY, A. S. et al. O desenvolvimento das competências de alunos formandos do curso de Administração: um estudo de modelagem de equações estruturais. Revista de Administração, São Paulo, v.44, n.3, p. 265-278, jul./ago./set. 2009. Disponível em: $<$ http://www.spell.org.br/documentos/ver/7298/o-desenvolvimento-das-competencias-dealunos-formandos-do-curso-de-administracao--um-estudo-de-modelagem-de-equacoesestruturais>. Acesso em: 21 out. 2013.

HAIR, J. F. et al. Fundamentos de métodos de pesquisa em Administração. Porto Alegre: Bookman, 2005.

HAIR, J. F. et al. Análise multivariada de dados. Bookman Editora, 2009.

INSTITUTO NACIONAL DE ESTUDOS E PESQUISAS EDUCACIONAIS ANÍSIO TEIXEIRA. Brasil supera média da OCDE de ingresso de estudantes. Brasília, 2013.

LE BOTERF, G. Desenvolvendo a competência dos profissionais. Porto Alegre: Artmed, 2003. 
MARINHO, S. V.; POFFO, G. D. Qualidade na percepção discente do curso de Administração. Revista GUAL, Florianópolis, v.6, n.2, p. 210-230, abr. 2013. Disponível em: $<$ https://periodicos.ufsc.br/index.php/gual/article/view/19834535.2013v6n2p210/24574>. Acesso em: 19 ago. 2014.

MILKOVITCH. G.T. BOUDREAU, J.W. Avaliação de Recursos Humanos. São Paulo: Atlas, 2006.

PRAHALAD, C. K.; HAMEL, G. Competindo pelo futuro: estratégias inovadoras para obter controle do seu setor e criar os mercados de amanhã. Rio de Janeiro: Elsevier, 2005.

RAMOS, E.; BENTO, S. As competências: quando e como surgiram. In: CEITIL, M. (Org.). Gestão e desenvolvimento de competências. Lisboa: Sílabo, 2007. p. 87-118.

RUAS, R. Desenvolvimento de competências gerenciais e contribuição da aprendizagem organizacional. In: FLEURY, M. T. L.; OLIVEIRA JR, M. M. (Org.) Gestão estratégica do conhecimento: integrando aprendizagem, conhecimento e competências. São Paulo: Atlas, 2010. p. 242-269.

SPENCER, JR., L.; SPENCER, S. Competence at work: models for superior performance. New York: John Wiley \& Sons, 1993.

TEIXEIRA, E. B.; WISSMANN, A. D. M. O ensino de Administração da UNIJUÍ: quatro décadas de história. Revista GUAL, Florianópolis, v.6, n.1, p. 156-175, jan. 2013. Disponível em:< https://periodicos.ufsc.br/index.php/gual/article/view/1983-

4535.2013v6n1p156/23991>. Acesso em: 19 ago. 2014.

UNIVERSIDADE FEDERAL DO CEARÁ. Projeto Pedagógico do Curso de

Administração. [Fortaleza], set. 2006. Disponível em:

$<$ http://www.si3.ufc.br/sigaa/public/curso/ppp.jsf?lc=pt_BR\&id=657452>. Acesso em: 9 out. 2013. 